\title{
Features and Teaching/Learning Activities Used In Educational Android Mobile Applications to Teach Quranic Arabic Vocabulary
}

\author{
A.R. Salam, F.Y. Mustaffa, N.H. Mohd Sharif, A. Sirri
}

\begin{abstract}
Today, the use of mobile devices such as smartphones and tablets has become truly ubiquitous. This has created an opportunity for mobile learning to prosper. Mobile learning applications have become so popular that there are thousands of developers and tens of thousands of educational apps on numerous subjects, including language learning, which can be easily downloaded and installed on mobile devices. One area of interest for Muslims is Quranic Arabic vocabulary learning. This qualitative exploratory study aims to examine all Quranic Arabic vocabulary learning applications provided on the Google Play Store website through content analysis in order to determine their features and the teaching activities. Data was gathered both from the 'product detail' page on the Play Store and from the testing of the application by the researchers. The findings of this study indicate that most Quranic Arabic vocabulary mobile apps deliver their lessons through a textual interface though there are several apps which also include pictures, audio, and videos in their lessons. Many apps also provide exercises in the form of translation, matching items, and sentence completion. However, only four apps provide assessments. As a conclusion, this exploratory study has shed some light on the current state of Quranic Arabic vocabulary mobile apps in terms of their features and activities and it is hoped that more apps will be developed in the near future to cater to the needs of millions of Muslim adults who want to improve their devotional practices.
\end{abstract}

Keywords: Android Applications, MALL, Mobile Learning Applications, Quranic Arabic Vocabulary.

\section{INTRODUCTION}

Today, the use of mobile devices such as smartphones and tablets has become truly ubiquitous. In many countries of the world, including Muslim majority countries like Malaysia, mobile device penetration is phenomenal. This has created an opportunity for mobile learning to prosper. Mobile learning applications have become so popular that there are thousands of developers and tens of thousands of educational apps on numerous subjects, including language learning, which can be easily downloaded and installed on mobile devices. One area of interest for Muslims is Quranic Arabic vocabulary learning. This is because the majority of Muslims in the world, more than 80 percent, are not Arabic speakers

Revised Version Manuscript Received on April 19, 2019.

A.R. Salam, Language Academy, Faculty of Social Sciences and Humanities, Universiti Teknologi Malaysia, Skudai, Johor, Malaysia.

F.Y. Mustaffa, Language Academy, Faculty of Social Sciences and Humanities, Universiti Teknologi Malaysia, Skudai, Johor, Malaysia.

N. Mohd Sharif, Language Academy, Faculty of Social Sciences and Humanities, Universiti Teknologi Malaysia, Skudai, Johor, Malaysia.

A. Sirri, Language Academy, Faculty of Social Sciences and Humanities, Universiti Teknologi Malaysia, Skudai, Johor, Malaysia.
(Abdullah \& Pathan, 2013). Understanding of the language of the Qur'an or Qur'anic Arabic is important for Muslims to enhance their devotional activities such as performing Salah or reciting the Qur'an (Elobaid, Hameed, \& Eldow, 2014). As Muslim adults get older, this area of religious practise becomes more important for them. One of the solutions to satisfy this segment of the Muslim population is to offer them Quranic Arabic vocabulary lessons through the use of mobile applications.

\section{OBJECTIVES}

This qualitative exploratory study aims to examine all Quranic Arabic vocabulary learning applications provided on the Google Play Store website through content analysis in order to determine their features and the vocabulary teaching activities that they provide to users. Unlike dedicated English vocabulary mobile applications which, in our last count, are more than three hundred in number (Sirri, Azizan, Mustaffa, \& Salam, 2018), dedicated Quranic Arabic vocabulary mobile applications are very few in number. Thus, this exploratory study will help us determine the number of Quranic Arabic mobile applications available to users today and to explore the features and teaching activities that they offer to users.

\section{METHODOLOGY}

This study employed content analysis approach in its data collection methodology. Content analysis approach is the best at giving a complete view to the mobile apps (Izahar et al., 2017). In order to find the relevant Quranic Arabic vocabulary mobile applications to analyze, we did a search in Google Play Store website using the keywords "Quranic Arabic" and "Understanding Arabic". The search found nearly 300 results. However, after discarding redundancies and non-relevant applications, we found that there were only 11 mobile applications (listed in Table 1 below) that truly fit the criteria of 'Quranic Arabic vocabulary mobile application'. After determining the number of applications to be studied, we employed the content analysis approach in analyzing them.

First, the 'product detail' page of mobile application was analyzed to glean relevant information from them such as the name of the application, the developer's company and website URL, the version of the application, the number of times it has 
International Conference on Recents Advancements in Engineering and Technology (ICRAET-18) |15th and 16th March 2019|Siddhartha Institute of Technology \& Sciences, Telangana, India.

been installed, and the ratings it received. Then, each mobile application was opened and used in order to find out their features and the learning activities employed. The data collected, as well as other relevant information, was then recorded in a Microsoft Excel file to facilitate data analysis.

Table 1: List of Quranic Arabic Vocabulary Mobile Applications in Google Play Store

\begin{tabular}{|c|c|c|c|c|}
\hline $\begin{array}{l}\text { App } \\
\text { Code }\end{array}$ & App Name & Developer & $\begin{array}{l}\text { Install } \\
\text { No. }\end{array}$ & Rating \\
\hline A1 & $\begin{array}{l}\text { Quranic: } \\
\text { Quran arn } \\
\text { Arabic }\end{array}$ & Busypeople & 10000 & 4.8 \\
\hline A2 & $\begin{array}{l}\text { Learn Quran - } \\
\text { Arabic } \\
\text { Learning App }\end{array}$ & Blue Yeti Inc & 10000 & 4.8 \\
\hline $\mathrm{A} 3$ & $\begin{array}{l}\text { Learn Arabic } \\
\text { Quran Words }\end{array}$ & Skylight & 50000 & 4.7 \\
\hline A4 & $\begin{array}{l}\text { e-iqra } \\
\text { Quranic Arabic }\end{array}$ & $\begin{array}{l}\text { Transformations } \\
\text { Unlimited }\end{array}$ & 10000 & 4.5 \\
\hline A5 & Quranic Words & Droid Dreams & 10000 & 4.8 \\
\hline A6 & $\begin{array}{l}\text { Learn Quran \& } \\
\text { Arabic } \\
\text { Grammar }\end{array}$ & Grammic & 1000 & 4.1 \\
\hline A 7 & $\begin{array}{l}\text { Quran Coach } \\
\text { Vocabulary }\end{array}$ & Mirath LLC & 5000 & 4.6 \\
\hline A8 & $\begin{array}{l}\text { Quran } \\
\text { Progress-Learn } \\
\text { and } \\
\text { Understand the } \\
\text { Quran }\end{array}$ & Quran Progress & 10000 & 4.7 \\
\hline A9 & $\begin{array}{l}\text { Learn Quran } \\
\text { Vocabulary } \\
\text { Gold }\end{array}$ & Smartappsweb & 1000 & 4.5 \\
\hline A10 & AnalyzeQuran & Logic-unit & 10000 & 4.9 \\
\hline A11 & Learn Quran & $\begin{array}{l}\text { Understand } \\
\text { Al-Qur'an } \\
\text { Academy }\end{array}$ & 50000 & 4.6 \\
\hline
\end{tabular}

\section{FINDINGS AND DISCUSSION}

Table 2 depicts the features and teaching/learning activities which are present in available Quranic Arabic vocabulary mobile applications on Google Play Store as of March 2019. The features and activities are divided into five categories which are lessons, exercises, assessments, motivational elements, and other elements.

Table 2: Features and Activities in Qur'anic Arabic Mobile Applications

\begin{tabular}{|l|l|}
\hline $\begin{array}{l}\text { Features in Quranic Arabic } \\
\text { Vocabulary } \\
\text { Mobile Applications }\end{array}$ & Relevant Apps \\
\hline $\begin{array}{l}\text { Lesson stages - unskippable linear } \\
\text { lessons }\end{array}$ & A1, A2, A4, A9 \\
\hline $\begin{array}{l}\text { Lesson stages - skippable non-linear } \\
\text { lessons }\end{array}$ & A3, A7 \\
\hline Rank student level before lessons & A1, A2 \\
\hline Lessons via text as medium & A1, A2, A3, A4, \\
& $\begin{array}{l}\text { A5, A6, A7, A8, } \\
\text { A9, A10, A11 }\end{array}$ \\
\hline Part of lessons via audio as medium & A2, A3, A7, A8 \\
\hline
\end{tabular}

\begin{tabular}{|c|c|}
\hline f vocabulary & \\
\hline $\begin{array}{l}\text { Parts of lessons via graphics as } \\
\text { medium }\end{array}$ & A4 \\
\hline Parts of lessons via video as medium & $\mathrm{A} 2, \mathrm{~A} 3, \mathrm{~A} 6, \mathrm{~A} 11$ \\
\hline $\begin{array}{l}\text { Gamification elements (achievement } \\
\text { badges, score board, progress } \\
\text { tracking, } 5 \text { lives) }\end{array}$ & $\begin{array}{l}\text { A1, A2, A3, A4, } \\
\text { A5, A7, A8, A9 }\end{array}$ \\
\hline Multiple language support & A4 \\
\hline Item Matching Exercises & $\mathrm{A} 1, \mathrm{~A} 2, \mathrm{~A} 4$ \\
\hline Sentence completion exercises & $\mathrm{A} 1, \mathrm{~A} 2$ \\
\hline $\begin{array}{l}\text { English-Arabic two-way translation } \\
\text { exercise }\end{array}$ & $\begin{array}{l}\text { A1, A2, A3, A4, } \\
\text { A5, A6, A10 }\end{array}$ \\
\hline $\begin{array}{lll}\begin{array}{l}\text { Reinforcement } \\
\text { (right/wrong) }\end{array} & \text { via } & \text { feedback } \\
\end{array}$ & $\begin{array}{l}\text { A1, A2, A5, A6, } \\
\text { A8, A9 }\end{array}$ \\
\hline Game elements (word game, quests & $\mathrm{A} 4, \mathrm{~A} 5$ \\
\hline Flashcard exercises & $\mathrm{A} 7, \mathrm{~A} 8$ \\
\hline True / False Questions Assessment & $\mathrm{A} 1, \mathrm{~A} 6, \mathrm{~A} 7, \mathrm{~A} 9$ \\
\hline $\begin{array}{lll}\text { Multiple } & \text { Choice } & \text { Questions } \\
\text { Assessment } & & \\
\end{array}$ & A6 \\
\hline Matching quiz Assessment & A7, A9 \\
\hline Progress tracking & $\begin{array}{l}\mathrm{A} 1, \mathrm{~A} 2, \mathrm{~A} 3, \mathrm{~A} 4, \\
\mathrm{~A} 7, \mathrm{~A} 8, \mathrm{~A} 9\end{array}$ \\
\hline Sign-up requirement before use & $\mathrm{A} 1, \mathrm{~A} 2, \mathrm{~A} 4$ \\
\hline Offline lesson access (part/full) & $\mathrm{A} 1, \mathrm{~A} 2$ \\
\hline
\end{tabular}

Generally, Quranic Arabic vocabulary lessons were given in text format. This can be seen in all the applications with the exception of the A11 application which gives its lessons entirely in video format. Due to the Quran being "the preserved verbatim words of Allah" (Abdullah et al., 2016, pg. 3) i.e. text format, the applications allow users to have a sense of the familiarity and feel closer to the original source of the vocabularies. As mentioned by Hussain (2017), good MALL apps should be able to provide clear guide to users to the key concepts, skills and terms.

The explanation and description through the text format are found to support the statement as it provides users with better understanding of the flow of the lessons and the overall content. Furthermore, lessons were also given in picture form (A5) and audio form (A2, A3, A7, and A8). These elements guide the users in a more interactive environment as enhanced text, high quality image, audio and video recordings are among elements that bring together the multi-sensory experience necessary for language learning (Yaman, Senel \& Yesilel, 2015). For exercises, seven out of eleven apps use the translation method, mostly from Quranic Arabic to English in order to teach users. This is because the use of a familiar language to users which in this case would help them to be more motivated to understand the Arabic Language. "Upon learning these translations [as well], the students would also be able to explain the words used in the Quran for accurate exemplification and understanding (Azahari, 2014, pg. 9). Six apps also provide reinforcements by giving feedback to users' right or wrong answers. This will not only help them keep track of their progress but also will motivate them to continue learning (Ok, Kim, Kang, \& Bryant, 2016). 

gamification elements in their exercises. This could potentially make their apps attractive to users (Wankel \& Blessinger, 2012). Only four out of eleven apps provide assessments to users. This is probably due to the informal nature of the apps that "is more preferable to be used during the leisure time" (Ibrahim et al., 2012, pg. 84). Since the apps are perceived to be casual, they are normally designed not to test understanding of the users. This is among the reasons for the lack of assessment element in most of the featured apps.

To motivate users in learning, seven of the apps provide progress tracking elements in their apps. This is an essential element of a MALL app to support self-learning and self-improvement in which they can assess the progress or achievement of student (Hussain, 2017) and at the same time fits with the current lifestyle of users (Ibrahim et al., 2012). There are three of the apps which require users to sign-up before they begin the lessons. This sign up feature is seemed not to encourage users to use the apps because they would need a valid internet connection to get on the apps. Even though with valid internet connection, they might feel annoyed by having to input the data when they want to use the apps (Budiu, 2014) that they have no way to know whether the content of the apps would be of their interest or not. Not only that, some users are also worried that, the developer might be using their data for other purposes which would impose on their privacy. Finally, two of the apps provide their lessons completely offline. Even if offline accessibility would require users "to download a large amount of data at the initial startup" (Yu, Ally \& Tsinakos, 2017, pg. 236), it does not require a valid internet connection to be used. Without this feature, users' learning motivation would be low as well since the apps are not accessible to them when they have poor or no internet connection. This is supported by Vogel, Kennedy, and Kwok (2009) that students' motivation is highly required for them to engage with mobile devices for learning purposes. They would have no motivation to use the apps when they could not access these apps in an offline mode. Plus, a significant number of Muslims live in developing countries, therefore, they would not have great internet infrastructure so, this feature would be a great help to them.

\section{V.CONCLUSION}

Through this exploratory study, some preliminary knowledge on the features and activities present in the Quranic Arabic vocabulary mobile apps have been achieved. The development of Quranic Arabic vocabulary apps is still in its infancy by looking at the small number of the apps available on the Play Store if compared to English vocabulary apps. However, through the analysis of these apps, we can see that serious efforts have been exerted by some developers to deliver quality end-user apps which incorporate lessons, exercises, assessments, motivational elements, and also gamification and game elements in order to attract users to use them. All these features are similar with the elements featured in most top English vocabulary apps and thus it can be said that Quranic Arabic vocabulary apps are on the right track in offering quality end-user apps. It is hoped that more apps of this nature be developed in the near future in order to help
What is interesting is that two of the apps also include

millions of Muslims worldwide for the betterment of their devotional endeavours. This study provides future developers of Quranic Arabic applications with insights to make their applications better.

\section{ACKNOWLEDGMENT}

The authors would like to thank and acknowledge the Ministry of Education, Malaysia (FRGS research grant, VOT NO 5F087) and Language Academy, Universiti Teknologi Malaysia for the financial support of this research project.

\section{REFERENCES}

1. Abdullah, M. S., Hafizur Rahman, M. M., Pathan, A.-S. K. \&, Al Shaikhli I. F. (2016, November) A Practical and Interactive Web-Based Software for Online Quranic Arabic Learning. Paper presented at the 2016 6th International Conference on Information and Communication Technology for The Muslim World (ICT4M), Jakarta, Indonesia. Retrieved from https://www.researchgate.net/ publication/ 312485748_A_Practical_and_Interactive_Web-Based _Software_for_Online_Qur'Anic_Arabic_Learning.

2. Abdullah, M. S. \& Pathan, A.-S. K. (2013). Learning Qur'anic Arabic through interactive web-based software: A pragmatic approach in Language for Specific Purpose. In Information and Communication Technology for the Muslim World (ICT4M), 2013 5th International Conference on (pp. 1-6).

3. Azahari, L. (2014). Incorporating Quran Translations into Teaching English to Muslim Learners.

4. Budiu, R. (2014, March 2). Login Walls Stop Users in Their Tracks. Retrieved July 12, 2019, from https://www.nngroup.com/ articles/login-walls/

5. Elobaid, M., Hameed, K. \& Eldow, M. E. Y. (2014). Toward designing and modeling of Quran learning applications for android devices. Life Science Journal, 11(1), 160-171.

6. Hussin, S. (2017). Mobile Learning: Future Trends and Challenges in Education [PowerPoint slides].

7. Ibrahim, N.J., Mohd Yusoff, M.Y.Z., Razak, Z. \& Raja Yusof, R.J. (2012) Mobile application of Quran and Arabic language for interactive and self-learning assistant: A review. In: The 2nd Annual International Qur'anic Conference 2012, 22-23 Feb 2012, University of Malaya.

8. Izahar, S., Lean, Q.Y., Abdul Hameed, M., Kumar Murugiah, M., Patel, R., \& Al-Worafi, Y., Wui W. T., \& Ming, L C. (2017). Content Analysis of Mobile Health Applications on Diabetes Mellitus. Frontiers in Endocrinology. 8. 318. 10.3389/fendo.2017.00318.

9. Ok, M. W., Kim, M. K., Kang, E. Y. \& Bryant, B. R. (2016). How to find good apps: An evaluation rubric for instructional apps for teaching students with learning disabilities. Intervention in School and Clinic, 51(4), 244-252.

10. Sirri, A., Azizan, A. R., Mustaffa, F. Y., \& Salam, A. R. (2018, June) Common Features in Popular Android Vocabulary Learning Apps. Paper presented at the 10th Language for Specific Purposes International Conference and 11th Global Advances in Business Communication Conference (LSP-GABC2018): Empowering future 
talents through language and communication, Senai, Johor, Malaysia. Retrieved from https://seminar.utmspace.edu.my/lspgabc2018/Doc/ 17.pdf

11. Vogel, D., Kennedy, D. M., \& Kwok, R. (2009). Does using mobile device applications lead to learning? Journal of Interactive Learning Research, 20, 469-485.

12. Wankel, C. \& Blessinger, P. (2012). Increasing student engagement and retention using immersive interfaces. Emerald Group Publishing Limited.

13. Yaman, İ., Şenel, M., \& Yeşilel, D. B. A. (2015). Exploring the extent to which ELT students utilise smartphones for language learning purposes. South African Journal of Education, 35(4).

14. Yu, S., Ally, M., \& Tsinakos, A. (Eds.). (2017). Mobile and ubiquitous learning: An international handbook. Springer.

\section{AUTHORS PROFILE}

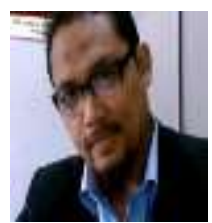

Abdul Rahim Salam is currently an Assoc. Professor at Language Academy, Faculty of Social Sciences and Humanities, UTM. He has been involved in teaching and researching CALL and TELL. He is also a member of APACALL. $\mathrm{He}$ is actively supervising $\mathrm{PhD}$ research students especially in the area related to Language Learning Technology and Communication.

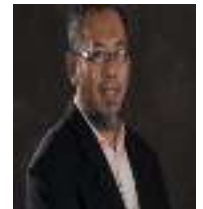

Faizal Yaimi Mustaffa is currently a Senior Lecturer and the Head of Language Lab at Language Academy Faculty of Social Sciences and Humanities, UTM. His research interest is related to Language Learning Technology and Communication, MALL, Quranic Arabic, and Vocabulary Learning.

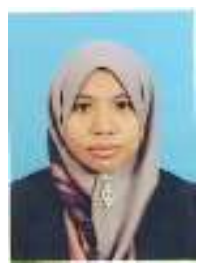

Nurhidayah Binti Mohd Sharif is currently working as a language instructor at Universiti Teknologi Malaysia. She is part of UTM MyLinE team. She is interested in the fields of English Language Teaching and Learning, Sociolinguistics and Health Communication.

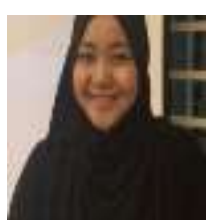

Azura Sirri is currently the English Courses Coordinator at Language Academy, Faculty of Social Sciences and Humanities, UTM. She does research that is related to Assessment and English Language Teaching and Learning. She is one of the master trainers of CEFR Malaysia appointed by KPM. 